\title{
Adaptive Sliding Mode Control for Semi-Active Structural Vibration Control
}

\author{
Abdelkrim SAIDI ${ }^{1 *}$, Khaled ZIZOUNI ${ }^{1}$, Boufeldja KADRI ${ }^{2}$, \\ Leyla FALI ${ }^{3}$, Ismail Khalil BOUSSERHANE ${ }^{1}$ \\ ${ }^{1}$ ArchiPEL Lab, TAHRI Mohamed University, PB 417, Bechar, Algeria \\ saidikarim2008@yahoo.fr (*Corresponding author),zizouni.khaled@univ-bechar.dz, bou_isma@yahoo.fr \\ ${ }^{2}$ Smart-Grids and renewable energy Lab, TAHRI Mohamed University, PB 417, Bechar, Algeria \\ kadri_bf@yahoo.fr \\ ${ }^{3}$ FIMAS Lab, TAHRI Mohamed University, PB 417, Bechar, Algeria \\ fali.leyla@pg.univ-bechar.dz
}

\begin{abstract}
Semi-active control methods were developed as an attempt to reduce vibration in structures exposed to earthquake motion and overcome the difficulties encountered due to the ignorance of the real seismic responses as well as its real proper time history. Furthermore, the availability of excellent devices such as the Magneto Rheological damper for developing an adequate control force based on control law estimation in real time has been urging researchers in the last few years to design a robust controller. In this case the big challenge is to find an appropriate controller design correlated with a performant algorithm for current or tension fitting. In this paper, an adaptive sliding mode controller is proposed for controlling the vibrations of a scaled three-story structure equipped with a MR damper installed on its ground floor. The scaled structure is exposed to the Boumerdès and theEl Centro's earthquake excitations. The numerical simulation results for the proposed adaptive controlled structure compared with the results obtained for the uncontrolled structure have shown the effectiveness, stability and robustness of the semi-active feedback adaptive control design.
\end{abstract}

Keywords: MR damper, Semi-active control, Seismic vibration, Adaptive law, SMC, Clipped optimal algorithm.

\section{Introduction}

Earthquakes are considered one of the most common natural hazards which cause human life losses and economic disasters.In a few seconds the earthquakes have killed more people than wars in several months. For example, in 1556 a strong earthquake killed in Shanxi and several other Chinese provinces about 830000 peoples (Talwani, 2014). Algeria didn't escape this either, an earthquake struck El-Asnam on 10 October 1980 and killed 2500 peoples. With a magnitude of 7.2 the main shockwave destroyed the city in the end (Roger et al., 2011).

During the last decade, many investigations have led to the development of new methodologies and designs for making different structures safe against these brutal dynamic motions. However, the control of structures was at the core of these theoretical and experimental investigations. The control structural strategy can be implemented by means of three systems, namely the passive, active and semi-active systems and hybrid control can be implemented by means of a combination of two of the three systems mentioned above. Passive control systems are devices which can enhance the stiffness or damping of a structure. These systems operate by exerting a control force on different structures in order to dissipate the energy of vibration caused by the earthquake excitation. However, these systems have a limited performance and can only achieve a slight reduction of structural vibrations. Despite this, passive systems are now widely used mainly because they do not depend on an external source of energy (Braz-César \& Carneirode Barros, 2013).

Active control systems are more complex than the passive ones. Otherwise, a high external power source is needed to serve actuators providing the desired control forces in real time. During the earthquake the active control system can calculate and exert control forces depending on the responses of the respective structures (Kobori, 1998). Semi-active control system is practically similar to the active system operating by means of a low power energy source. Therefore, the semi-active control devices are electrically or magnetically controllable viscosity devices which can be powered by just a batteries (Dyke et al., 1996). The design of the control algorithm is an important step in structural active control.Though, the appropriate law of control is necessary for the system to calculate the desired forces of control based on the structural responses in real time. Thus, the laws of command governing the control algorithm are divided into two classes. The first 
class called the classical class is a mathematical model based on Lyapunov stability theory of the controlled system (Jedda\&Douik, 2018). The other class called the intelligent class is operating algorithm without requiringthe mathematical model presentation of the system(Zizouni et al., 2019). In many cases a combination of the pervious classes is necessary, this is called hybrid algorithm (Wang et al., 2016).

$\mathrm{Xu}$ proposed a parametric study of the active mass damper design. The results are performed by an aero-elastic model of tall building tested in a wind tunnel (Xu, 1996). Pinelli et al. investigated the control of earthquake responses using two parallel tuned mass dampers and another perpendicular in three story asymmetrical building (Pinelli et al., 2014). In (Battaini, Casciati\&Faravelli, 1998) the authors designed a fuzzy logic controller to control an active mass damper. This device is implanted in three story frame subjected to an earthquake excitation. The results of this study have shown the effectiveness of the proposed controller in seismic structural vibrations reduction. Furthermore, Ras and Boumechra controlled a twelve story farm with an energy dissipation system. In which a diagonal fluid viscous damper is used to attenuate vibrations in the tested structure subjected to Boumerdès earthquake (Ras\&Boumechra, 2016). Zizouni et al. proposed a linear quadratic controller to control a MR damper for structural vibration suppression of scaled three story structure (Zizouni et al., 2017). Thus, Guclu and Yazici proposed an active control system using an active mass damper device commanded by a fuzzy logic and a PID controllers meant to attenuate structural vibrations caused by earthquakes because of the soil-structure interaction (Guclu\&Yazici, 2007).
This paper presents an adaptation for a nonlinear controller is proposed for controlling the vibrations of a scaled three-story structure subject to an earthquake excitation. In order to consider the uncertainties and the nonlinearities peculiar to the practical cases an adaptive sliding mode controller coupled to a clipped optimal algorithm is proposed for reducing the seismic vibrations of the tested structure while using a magneto-rheological damper. This structure was subjected to the El-Centro 1940 earthquake. The robustness of the proposed controller and the adaptation law are proved by comparing the simulation results related to the uncontrolled structure with those related to the adaptive sliding mode controlled structure.

The rest of the proposed paper is orderly organized as follows. The second section sets forth the magnetorheological damper and the equations related to its model, while in section 3 the test scaled structure is defined and the mathematical model of the controlled system is explained. Further on, in section 4 the controller and the adaptive law are formulated assuring the Lyapunov stability criterion. The numerical examples under the El-Centro 1940 and the Boumerdès 2003 earthquakes are presented and the comparison of the results is shown in section 5. Finally, this paper is closed by the drawn conclusion in the last section.

\section{The Magneto-Rheological Damper Model}

Recently, an attempt was made to get the present state of knowledge in semi active control

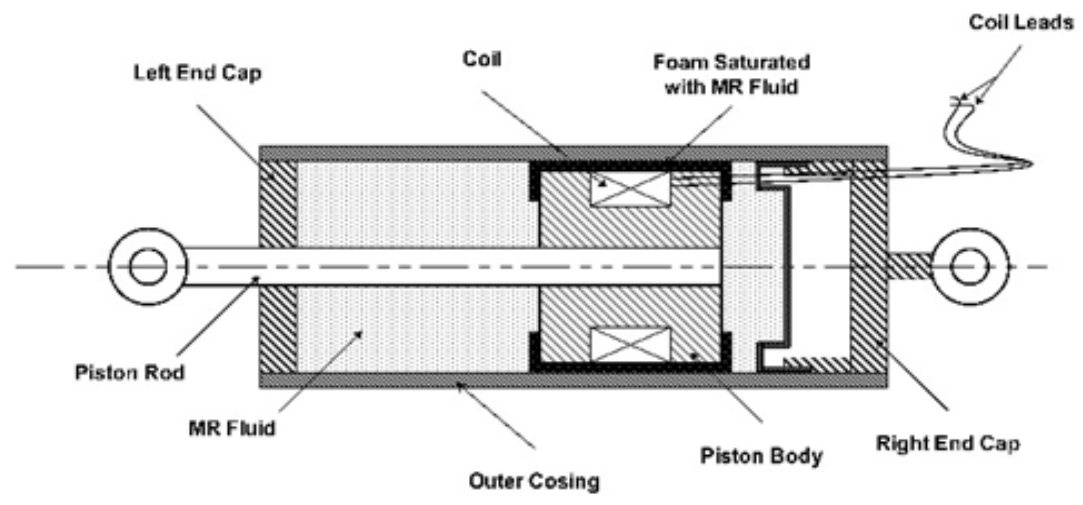

Figure 1. Cross section of MR damper body 
devices. One of the most used classes of semi active devices is the controllable fluid devices. These devices can vary their performance corresponding to received current or tension depending on the fluid types. Two fluids those are viable for these devices electro-rheological and magneto-rheological fluid. The proposed device is a magneto-rheological (MR) damper used to control structural vibrations caused by earthquake excitations shown in Figure 1. The MR damper is one of the suitable devices for structural control and the most used. This device is preferred for its simplicity, low energy operating and responds in milliseconds it can developed the desired force in $8 \mathrm{~ms}$. With a nonlinear behavior this device can operate in a high range of temperature namely from $-40 \mathrm{C}^{\circ}$ to $150 \mathrm{C}^{\circ}$. The MR damper fluid in the presence of a magnetic field can change its viscosity ranging from a linear viscous fluid to a semi-solid (Jadhav\&Gawade, 2014).

For this reason, the MR dampers have been developed and tested for structural vibrations control under dynamic loads. However, a number of studies focused on developing a mathematical model for representing the nonlinear behavior of the MR damper (Jansen \& Dyke,2000). The first description of the above-mentioned nonlinear behavior was a quasi-static model proposed in 1916 by Bingham (Bingham, 1916). An extension of the Bingham model was proposed in 1991 by (Gamota\&Filisko, 1991). Bouc proposed a model based on hysteretic behavior in 1967 (Bouc, 1967). By contrast, the Bouc-wen model which is the most used in the modelization of the MR damper behavior is a generalization of the Bouc model established by Wen in 1976 (Wen, 1976). As an alternative to considering the Bouc-Wen model as a basis for the MR damper behavior, an augmented model was proposed by(Dyke et al., 1996) based on the experimental validation of the Bouc-Wen model.

The augmented Bouc-Wen model is governed by the following equations

$$
\begin{aligned}
& c_{1} \dot{y}=c_{0}(\dot{x}-\dot{y})+k_{0}(x-y)+z \\
& \dot{z}=-|\dot{x}-\dot{y}| z|z|^{n-1}-(\dot{x}-\dot{y})|z|^{n}+A(\dot{x}-\dot{y}) \\
& \dot{y}=\frac{1}{c_{0}+c_{1}}\left[z+c_{0} \dot{x}+k_{0}(x-y)\right]
\end{aligned}
$$

where the force generated by the MR damper is

$f_{M R D}=c_{0}(\dot{x}-\dot{y})+k_{0}(x-y)+k_{1}\left(x-x_{0}\right)+z$

where $x$ and $\dot{x}$ are the damper's displacement and velocity, $v$ is the applied voltage, $k_{0}$ and $k_{1}$ correspond to the accumulator stiffness at low and high velocity, $c_{0}$ and $c_{1}$ correspond to the accumulator viscous damping at low and high velocity, $\gamma, \beta, n$, and $A$ are parameters giving the hysteresis form and $z$ is a multi-depending variable describing the hysteresis action of the output variable of the chosen device.

Moreover, the depending parameters on the current voltage applied to the MR damper are given by

$\alpha=\alpha_{a}+\alpha_{b} u$

$c_{1}=c_{1 a}+c_{1 b} u$

$c_{0}=c_{0 a}+c_{0 b} u$

$\dot{u}=-\eta(u-v)$

where $u$ is a phenomenological variable which represents the dynamics of the system, $v$ is the applied voltage and $\eta$ is a time response factor.

\section{The Tested Scaled Structure Model}

The tested structure is a scaled three-floor structure presented in Figure 2. This structure is subject to an earthquake load is controlled by using one MR damper which is installed on the ground floor.

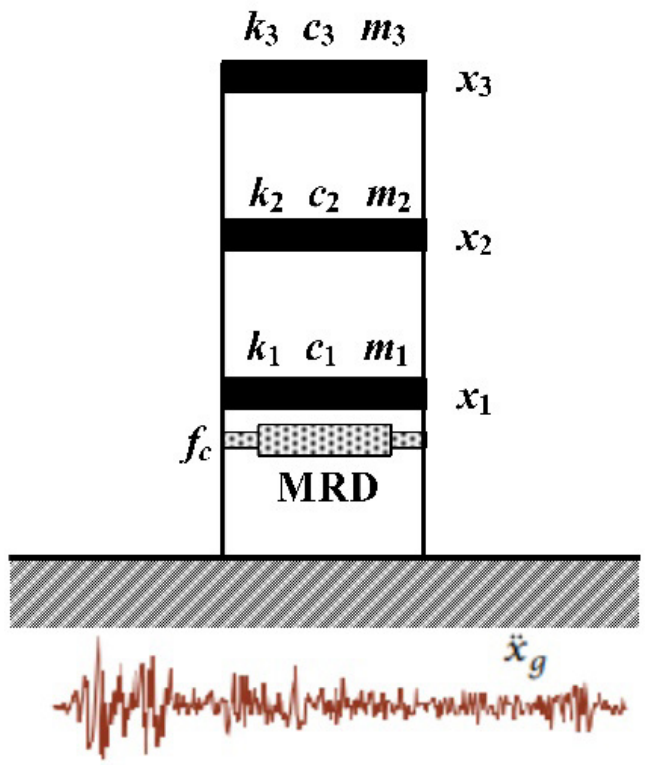

Figure 2. Tested scaled structure model 
The equation governing the time depending motion of the structural system equipped with MR damper as it is illustrated in Figure 2 can be written as follows

$M_{s} \ddot{x}+C_{s} \dot{x}+K_{s} x=M_{s} \Lambda \ddot{x}_{g}+\Gamma f_{c}$

Where $M_{s}, C_{s}$ and $K_{s}$ correspond to the matrices of mass, damping and stiffness of the scaled structure expressed as

$$
\begin{aligned}
& {\left[M_{s}\right]=\left[\begin{array}{ccc}
m_{1} & 0 & 0 \\
0 & m_{2} & 0 \\
0 & 0 & m_{3}
\end{array}\right]} \\
& {\left[C_{s}\right]=\left[\begin{array}{ccc}
c_{1}+c_{2} & -c_{2} & 0 \\
-c_{2} & c_{2}+c_{3} & -c_{3} \\
0 & -c_{3} & c_{3}
\end{array}\right]} \\
& {\left[K_{s}\right]=\left[\begin{array}{ccc}
k_{1}+k_{2} & -k_{2} & 0 \\
-k_{2} & k_{2}+k_{3} & -k_{3} \\
0 & -k_{3} & k_{3}
\end{array}\right]}
\end{aligned}
$$

$\ddot{x}, \dot{x}$ and correspond to the acceleration, velocity and displacement vector of the floor relative to the base, $\Lambda$ is the effect vector of the ground acceleration, $\Gamma$ the vector position of the MR damper and $f_{c}$ is the control force.

$$
\begin{aligned}
& \Lambda=\left[\begin{array}{lll}
1 & 1 & 1
\end{array}\right]^{T} \\
& \Gamma=\left[\begin{array}{lll}
-1 & 0 & 0
\end{array}\right]^{T}
\end{aligned}
$$

\section{Semi-active Control Algorithm for a Structure using an Adaptive SMC}

One of the most popular nonlinear control strategies in civil engineering structural vibration control is the sliding mode controller. Since its emergence in the early 1950s (Emel'yanov, 1957) the sliding mode control has been the subject of several works on structural control(Nguyen et al., 2006). However, this controller is considered as one of the robust and accurate controllerswhich under uncertainty conditions keepson obtaining the desired output based on high-frequency control switching (Young, Utkin \&Özgüner, 1999). Among, the main advantages of sliding mode control one can mention the insensitivity to bounded matched uncertainties and external disturbances with finite-time convergence and the reduction of the order of the controlled system deferential equations. On the other hand, the major obstacle in sliding mode implantation is the undesirable chattering phenomena caused by the finite frequency and amplitude oscillations.

In order to overcome this undesirable problem in the sliding mode control various strategies have been developed and conceived. Many results have been obtained in this area, the earliest being the extension of a second-order linear system to a first-order one. Furthermore, one should mentionthe boundary layer solution wherein a saturated function is introduced to the switching part of the controller. This controller used a discontinuous signal for correcting the dynamics of the system based on two control steps. The first step called the reaching phase consisted in pushing the system to the sliding trajectory in finite time and maintaining the motion further on. Thereafter, the second step called the sliding phase was to force the system's dynamics to commutate on the sliding surface (Yan, Spurgeon \& Edwards, 2017).

The nonlinear dynamic system can be described as $\dot{x}=f(x, t)+g(x, t) u$

where $x$ is the state vector, $u$ is the control input, $f(x)$ and $g(x)$ represents the smooth uncertain functions. The function $g(x)$ is supposed to be different from zero. The sliding surface can be presented as

$s=G e$

where $G$ is the coefficient matrix of switching sliding surface and $e$ is the tracking error. In the sliding phase when the system in (15) gets the sliding surface described as

$s(x)=0$

$\dot{s}(x)=0$

The derivative in (18) can be written as

$\dot{s}=\frac{\partial s}{\partial x} \dot{x}=\frac{\partial s}{\partial x}(f(x, t)+g(x, t) u)=0$

Suppose that the (19) has a solution denoted $u_{e q}(x, t)$ then the so-called equivalent control and the dynamics of the sliding motion is given by (Utkin, 1993)

$$
\left\{\begin{array}{c}
\dot{x}=f(x, t)+g(x, t) u_{e q}(x, t) \\
s(x)=0
\end{array}\right.
$$


Based on (15), (19) and (20) the equivalent control is given by

$u_{e q}(x, t)=-(s(x) g(x, t))^{-1} s(x) f(x, t)$

However, in the reaching phase the system is pushed to the sliding surface in finite time if the following condition is satisfied

$\dot{s}(x) \cdot s(x)<0$

Therefore the (22) can be written as

$\frac{\partial s}{\partial x}(f(x, t)+g(x, t) u) \cdot s(x)<0$

$s(x)$ and $\dot{s}(x)$ do not retain the positive or negative sign under variation of $u$ for this reason the second part of the command is proposed as (Khebbache \& Tadjine, 2013; Sudhir \& Swarup, 2018):

$u_{s}=K \cdot \operatorname{sgn}(s)$

where sgn is the signum function defined as

$$
\operatorname{sgn}(s)=\left\{\begin{array}{ccc}
-1 & \text { if } & s<0 \\
0 & \text { if } & s=0 \\
1 & \text { if } & s>0
\end{array}\right.
$$

To avoid the chattering problem the boundary layer solution is introduced and the (25) is given by (Khebbache \& Tadjine, 2013)

$u_{s}=K \cdot \operatorname{sat}(s / \xi)$

where $K>\mathrm{O}$ and $\operatorname{sat}(\cdot)$ is the saturation function defined as

$$
\operatorname{sat}(s / \xi)=\left\{\begin{array}{cc}
s / \xi & |s / \xi| \leq \xi \\
\operatorname{sgn}(s / \xi) & |s / \xi|>\xi
\end{array}\right.
$$

In which $\xi$ is the boundary layer thickness of the sliding surface. The control law of the sliding mode control (SMC) is defined as

$u_{S M C}=u_{e q}+u_{s}$

Until nowadays, several methods and strategies have been proposed in order to reduce the chattering effect in sliding mode control. For example, (Young, Utkin \& Özgüner, 1999) proposed a high order sliding mode controllers. The extended sliding mode with a fuzzy Backstepping was proposed in (Khebbache \& Tadjine, 2013).
These proposed methods proved the stability and the performance of the above-mentioned controlled system. However, the controller tends to generate a large input gain to compensate the unavailability of desired information regarding the uncertainties (Sudhir \& Swarup, 2018).

In this study, a sliding mode control algorithm with a gain-adaptation law for robust control of nonlinear systems is proposed to overcome the above-mentioned drawbacks.

In this case (28) can be written as

$u_{A S M C}=u_{e q}+u_{a s}$

where the term $u_{s}$ in (24) is adapted as follows

$u_{a s}=\hat{K} \cdot \operatorname{sat}(s)$

Where $\widehat{K}$ is an adjustable gain constant and the adaptive law defined as

$\dot{\bar{K}}=\frac{1}{\alpha}|s|$

where $\boldsymbol{\alpha}$ is the adaptation gain. The adaptation speed $\dot{K}$ can be adjusted by $\boldsymbol{\alpha}(\boldsymbol{\alpha}>0)$ and, as such, the choice of an appropriate $\boldsymbol{\alpha}$ can affect the efficacy of the control law.

Using the Lyapunov stability the adaptation error is written as

$\hat{e}=\widehat{K}-K_{d}$

Where $K_{d}$ is considered to be the terminal solution of (24), where $\left(K_{d}>d\right)$ and $d$ is the lumped uncertainty related to roll motion.

Define the candidate function as follows

$V=\frac{1}{2} s^{2}+\frac{1}{2} \alpha e^{-2}$

The first-time derivation of (33) can be written as

$\dot{V}=s \dot{s}+\alpha \dot{e} \dot{e}$

Based on (16), (30), (31) and (32) the above equation becomes

$\dot{V}=s(e \dot{e})+\alpha\left(\widehat{K}-K_{d}\right) s \cdot \operatorname{sgn}(s)$

$\dot{V}=s(d-\hat{K} \cdot \operatorname{sgn}(s))+\alpha\left(\widehat{K}-K_{d}\right) s \cdot \operatorname{sgn}(s)$

$\dot{V}=d \cdot s-K_{d} \cdot|s|$

The stability is guaranteed if

$V \dot{V}<0$ 
The term of $V$ presented in (33) is always positive and the stability is assured only if the term of the (37) is always negative.

Therefore, the proposed control correlated with a self-tuning adaptive law is illustrated through a block diagram in Figure 3. As we know the MR damper can't be commanded directly but through a signal voltage. For this reason, a clipped optimal algorithm was designed to control the current driver (Figure 3). Furthermore, this on-off switch algorithm based on Heavy step function adjusted the current signal to generate the desired force through the MR damper (Zizouni et al., 2017; Dyke et al., 1997).

$v=v_{\max } H\left(\left(f_{d}-f_{M R D}\right) f_{M R D}\right)$

where $v_{\max }$ is the maximum voltage of the current driver, $H\{$.$\} is a function describing the$ Heaviside step, $f_{d}$ is the desired force of control calculated by the controller, $f_{M R D}$ is the generated force of the MR damper and $f_{c}$ is the control force of the system.

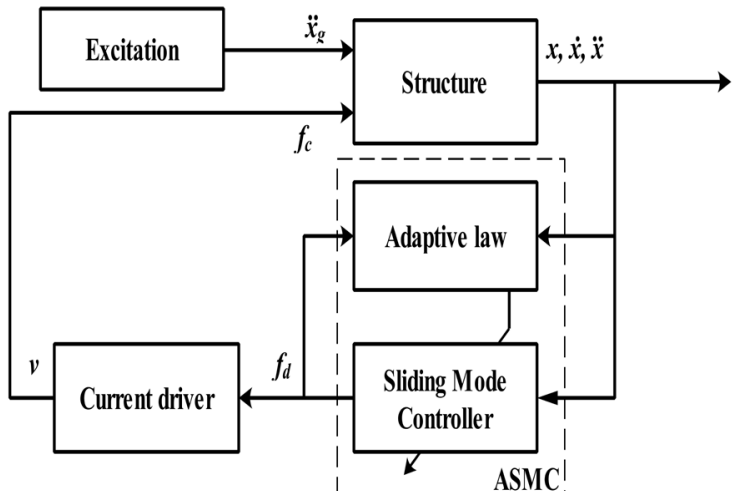

Figure 3. Block diagram with adaptive sliding mode controller

\section{Numerical Example}

For the proposed control algorithm evaluation numerical examples were adopted (Zizouni et al., 2019; Zizouni et al., 2017). The tested building is a three-story scaled structure equipped with a magneto-rheological damper installed on the ground floor (Figure 2). This structure was subject to two time-scaled earthquake excitation records pertaining to the El-Centro earthquake of 1940 and Boumerdès 2003, as illustrated in Figures 4 and 5.

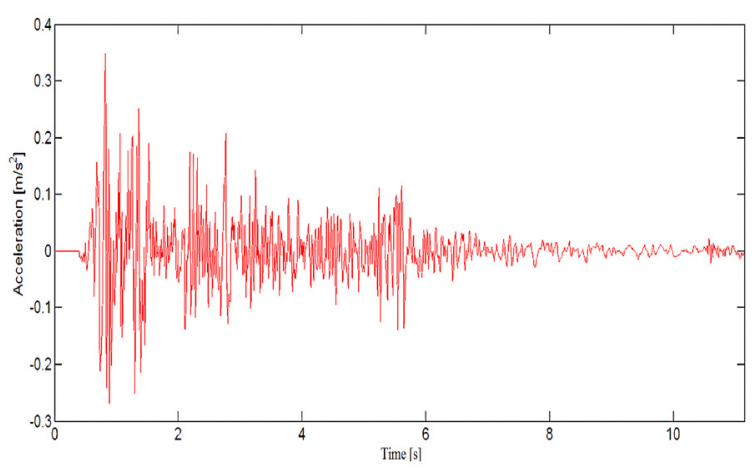

Figure 4. The NS Time-scaled component of the 1940 El-Centro earthquake

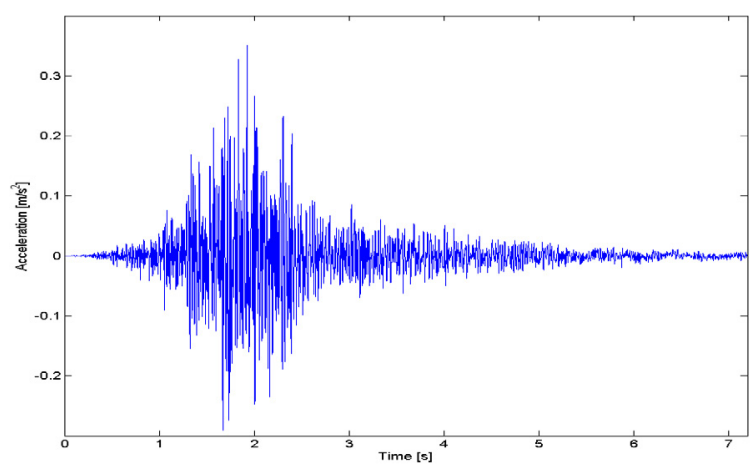

Figure 5. The NS Time-scaled component of the 2003 Boumerdès earthquake

The simulation results pertaining to the compared uncontrolled and the adaptive sliding mode controlled structure are depicted in Figures 6, 7, 8 and 9. The displacement of the first, second and the third floors under the El Centro 1940 and Boumerdès 2003 earthquakes are illustrated and the vibration reduction is clearly depicted in the Figures 6 and 7.
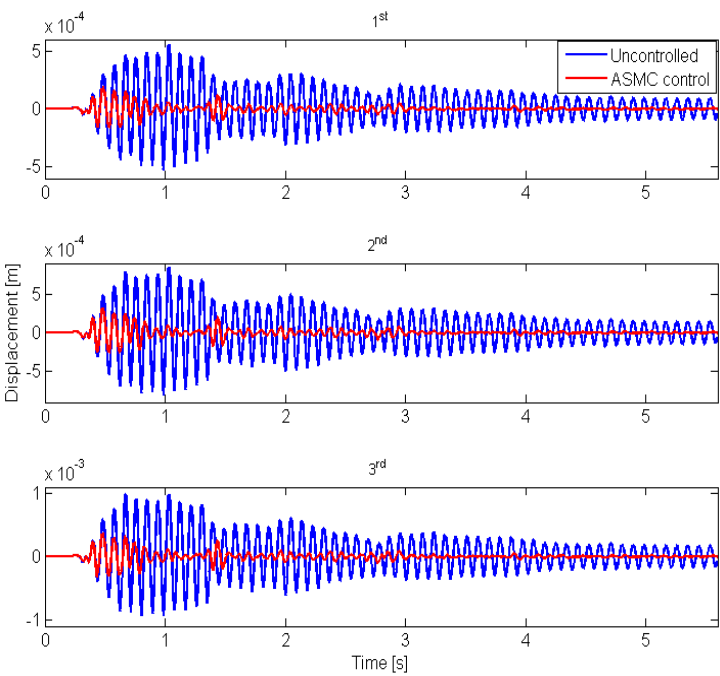

Figure 6. Displacement responses of the $1^{\text {st }}, 2^{\text {nd }}$ and $3^{\text {rd }}$ floors under El Centro 1940 earthquake 

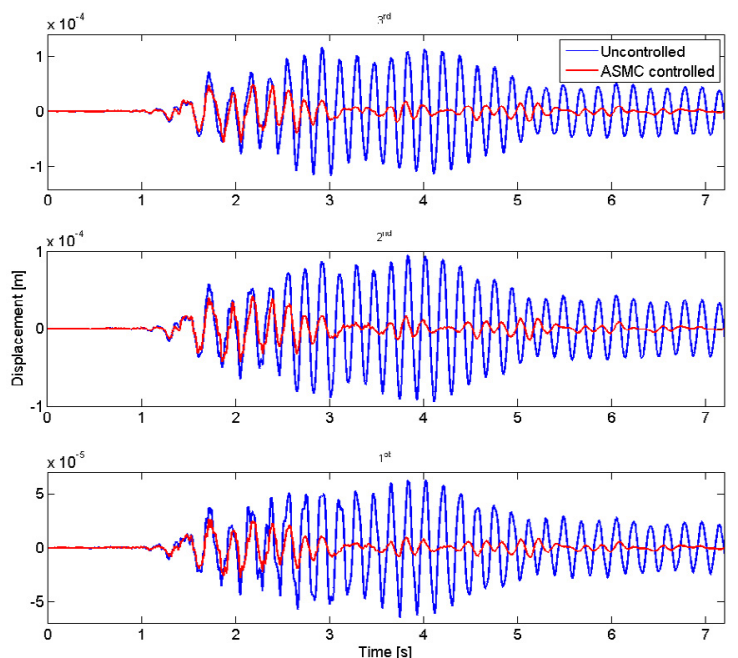

Figure 7. Displacement responses of the $1^{\text {st }}, 2^{\text {nd }}$ and $3^{\text {rd }}$ floors under Boumerdès 2003 earthquake
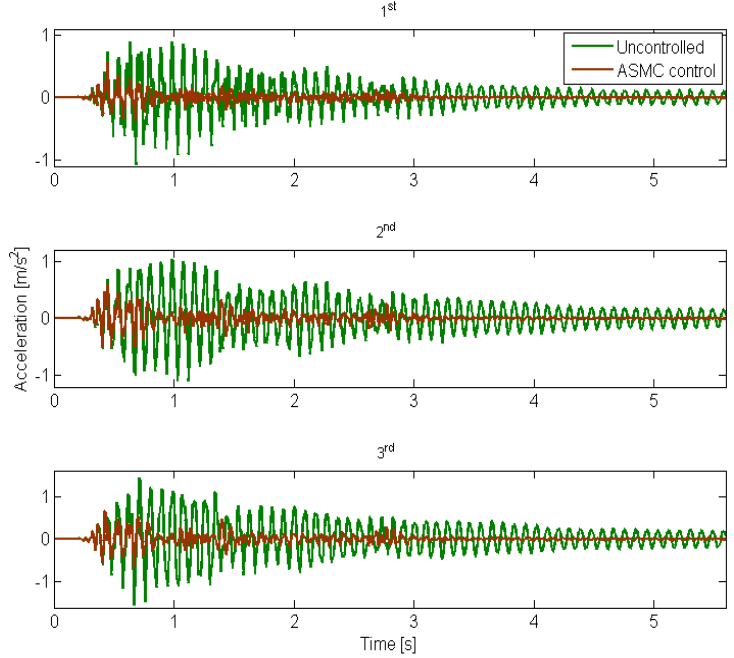

Figure 8. Acceleration responses of the $1^{\text {st }}, 2^{\text {nd }}$ and $3^{\text {rd }}$ floors under the El Centro 1940 earthquake
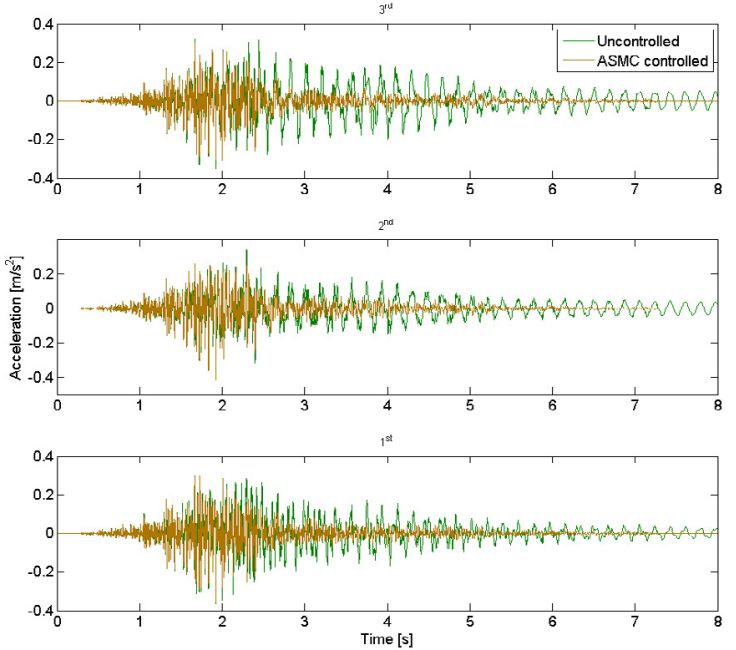

Figure 9. Acceleration responses of the $1^{\text {st }}, 2^{\text {nd }}$ and $3^{\text {rd }}$ floors under the Boumerdès 2003 earthquake
Therefore, the structural vibration of the proposed strategy is illustrated. The Figures 8 and 9 depicts the structural acceleration of the first, second and the third floors of the uncontrolled structure compared to those of the semi-active controlled structure under the El Centro 1940 and the Boumerdès 2003 earthquake excitations.

Furthermore, the time responses of the current driver command voltage applied to the MR damper are shown in the Figures 10 and 11. The voltage response switched between the two values $0 \mathrm{~V}$ and the maximum voltage basing on (39).

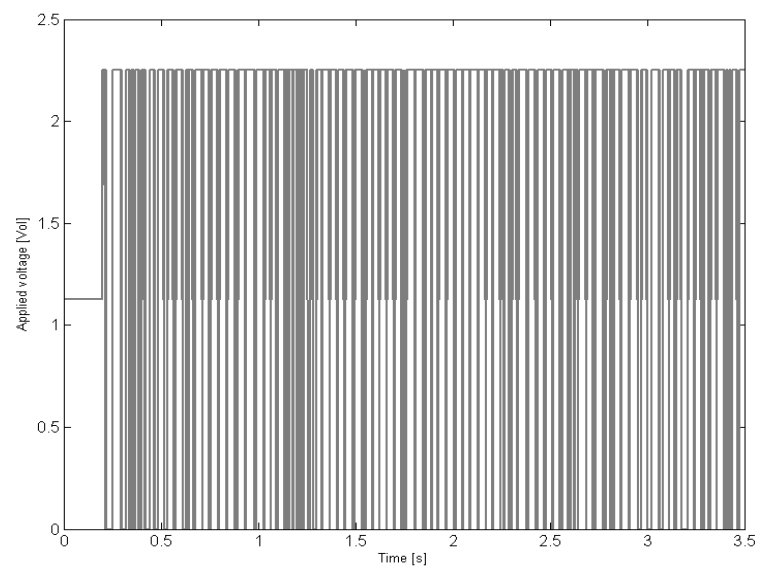

Figure 10. Time response voltages applied to MR damper driver under the El Centro 1940 earthquake

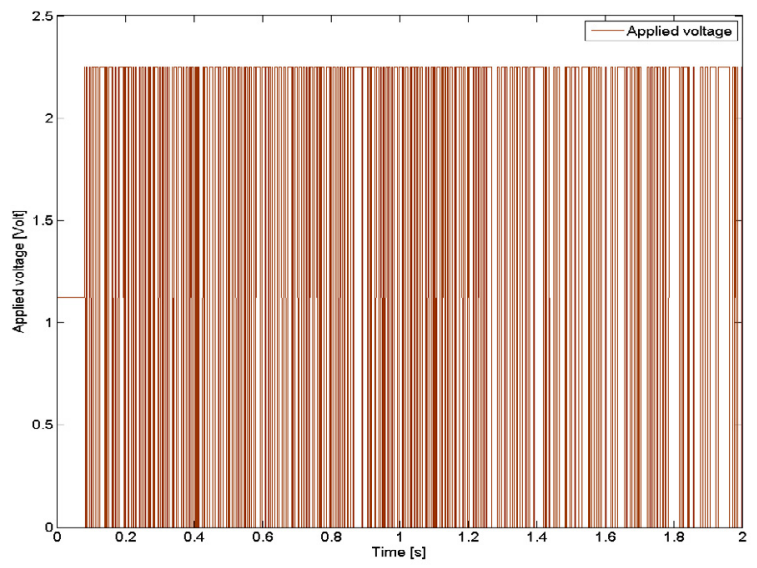

Figure 11. Time response voltages applied to MR damper driver under the Boumerdès 2003 earthquake

Where $\ddot{x}_{a i}, d_{i}$ and $m_{i}$ are the acceleration, inter-storey drift ratio and mass at the ith floorrespectively, while $\ddot{x}_{a i}^{\text {max }}, F_{b}^{\max }$ and $d_{i}^{\text {max }}$ are the peak floor acceleration, base shear and interstorey drift ratio of the uncontrolled structure. 
Table 1. Evaluative indices under both of the El Centro 1940 and the Boumerdès 2003 earthquake excitations

\begin{tabular}{|c|c|c|c|c|}
\hline Index & $\begin{array}{c}J_{1}=\frac{\max \left|d_{i}\right|}{d_{i}^{\text {max }}} \\
\text { Inter storey drift }\end{array}$ & $\begin{array}{c}J_{2}=\frac{\max \left|\ddot{x}_{a i}\right|}{\ddot{x}_{a i}^{\text {max }}} \\
\text { Floor acceleration }\end{array}$ & $\begin{array}{c}J_{3}=\frac{\max \left|\sum m_{i} \ddot{x}_{a i}\right|}{F_{b}^{\text {max }}} \\
\text { Base shear }\end{array}$ & $\begin{array}{c}J_{4}=\frac{\max \left\|d_{i}\right\|}{\left\|d_{i}^{\text {max }}\right\|} \\
\text { Peak control force }\end{array}$ \\
\hline \multicolumn{5}{|c|}{ Under the El Centro 1940 earthquake excitation } \\
\hline SMC & 0.421 & 0.455 & 0.402 & 0.394 \\
\hline ASMC & 0.399 & 0.428 & 0.395 & 0.373 \\
\hline LQG (Bozorgvar \& Zahrai, 2019) & 0.740 & 0.781 & 0.881 & 0.615 \\
\hline \multicolumn{7}{|l|}{ Under Boumerdès 2003 earthquake excitation } \\
\hline SMC & 0.504 & 1.076 & 0.927 & 0.454 \\
\hline ASMC & 0.496 & 1.064 & 0.922 & 0.455 \\
\hline
\end{tabular}

Furthermore, to investigate and evaluate the success of the proposed adaptive control, some evaluative indices are calculated. These indices evaluate the effectiveness of the control of the structure with MR damper commanded by the proposed adaptive sliding mode controller. These indices and their values are listed in the Table 1 and compared to those calculated using a linear quadratic Gaussian by (Bozorgvar \& Zahrai, 2019).

\section{Conclusion}

The robustness of the proposed sliding mode control reinforced by an adaptation law in earthquake vibration elimination for a scaled tested structure has been investigated thoroughly

\section{REFERENCES}

1. Battaini, M., Casciati, F. \& Faravelli, L. (1998). Fuzzy Control of Structural Vibration. An Active Mass System Driven by a Fuzzy Controller, Earthquake Engineering Structural Dynamics, 27(11), 1267-1276.

2. Bingham, E. C. (1916). An Investigation of the Laws of Plastic Flow, U.S. Bureau of Standards Bulletin, 13(2), 309-353.

3. Bouc, R. (1967). Forced Vibrations of a Mechanical System with Hysteresis. In Proceedings of the $4^{\text {th }}$ Conference on Non-linear Oscillations, Prague, Czech Republic (pp. 315).

4. Bozorgvar, M. \& Zahrai, S. M. (2019). Semi-active seismic control of buildings in this paper. Hence, the effectiveness of the presented controller is shown by the numerical simulation results. The depicted simulation results pertaining to the controlled structure and to the uncontrolled one proved the performance of the proposed controller in seismic vibrations elimination in a vivid manner.They indicated the effectiveness of the MR damper generated by the proposed adaptive strategies in eliminating earthquake structural vibrations. Nevertheless, this robustness was also proved by the compared evaluation results pertaining to the sliding mode control (SMC) and the adaptive sliding mode control (ASMC) strategy under both the El Centro 1940 and Boumerdès 2003 seismic excitations.

using magnetorheological damper and adaptive neural-fuzzy intelligent controller optimized with genetic algorithm, Journal of Vibration and Control, 25(2), 273-285.

5. Braz-César, M. \& Carneiro de Barros, R. (2013). Passive control of civil engineering structures. In Proceedings of $4^{\text {th }}$ International Conference on Integrity, Reliability and Failure of Mechanical Systems (pp. 575-576). PAPER REF: 4756.

6. Dyke, S. J., Spencer Jr., B. F., Sain, M. K. \& Carlson, J. D. (1996). Experimental verification of semi-active control strategies using acceleration feedback. In Proceedings of the $3^{\text {rd }}$ International Conference on Motion and Vibration Control, III (pp. 291-296). 
7. Dyke, S. J., Spencer Jr., B. F., Sain, M. K. \& Carlson, J. D. (1996). Seismic Response Reduction Using Magnetorheological Dampers, IFAC Proceedings Volumes, 29(1), 5530-5535.

8. Emel'yanov, S.V. (1957). The way of obtaining complicated laws of control using only an error signal and its first derivative, Avtomatika $i$ Telemekhanika, 18(10), 873-885.

9. Gamota, D. R. \& Filisko, F. E. (1991). Dynamic Mechanical Studies of Electrorheological Materials: Moderate Frequencies, Journal of Rheology, 35(3), 399-425.

10. Guclu, R. \& Yazici, H. (2007). Fuzzy Logic Control of a Non-linear Structural System against Earthquake Induced Vibration, Journal of Vibration and Control, 13(11), 1535-1551.

11. Jadhav, A. \& Gawade, S. S. (2014). Modern Applications of Electrorheological (ER) Fluids, International Journal of Emerging Technologies and Applications in Engineering, Technology and Sciences, 6(2), 112-118.

12. Jansen, L. M. \& Dyke, S. J. (2000). Semi-Active Control Strategies for MR Dampers: A Comparative Study, Journal of Engineering Mechanics, 126(8), 795-803.

13. Jedda, O. \& Douik, A. (2018). Discretetime Integral Sliding Mode Control with Anti-windup, Studies in Informatics and Control, 27(4), 413-422. DOI: 10.24846/ v27i4y201805

14. Khebbache, H. \& Tadjine, M. (2013). Robust Fuzzy Backstepping Sliding Mode Controller for a Quadrotor Unmanned Aerial Vehicle, Journal of Control Engineering and Applied Informatics, 15(2), 3-11.

15. Kobori, T. (1988). State-of-the Art Report Active Seismic Response Control. In Proceedings of the ninth World Conference on Earthquake Engineering - $9^{\text {th }}$ WCEE, VIII (pp. 435-446). PAPER REF: SE-R2.

16. Nguyen, T. H., Kwok, N. M., Ha, Q. P., Li, J. \& Samali, B. (2006). Adaptive Sliding Mode Control for Civil Structures using Magnetorheological Dampers. In Proceedings of the $23^{\text {rd }}$ International Symposium on Automation and Robotics in Construction - ISARC, Tokyo, Japan (pp. 636-641).

17. Pinelli, J. P., Chen, K., Gutierrez, H. \& Rusovici, R. (2014). Control of seismic vibrations of a 3D asymmetrical 3 -story building model with three TMD's. In Proceedings of the 9th International Conference on Structural Dynamics, EURODYN, Porto, Portugal (pp. 1689-1696).

18. Ras, A. \& Boumechra, N. (2016). Seismic energy dissipation study of linear fluid viscous dampers in steel structure design, Alexandria Engineering Journal, 55(3), 2821-2832.

19. Roger, J., Hebert, H., Ruegg, J. C. \& Briole, P. (2011). The El Asnam 1980 October 10 inland earthquake: a new hypothesis of tsunami generation, Geophysical Journal International, 185(3), 1135-1146.

20. Sudhir, N. \& Swarup, A. (2018). On adaptive sliding mode control for improved quadrotor tracking, Journal of Vibration and Control, 24(14), 3219-3230.

21. Talwani, P. (2014). Intraplate Earthquakes. Cambridge University Press.

22. Utkin, V. I. (1993). Sliding Mode Control Design Principles and Applications to Electric Drives, IEEE Transactions on Industrial Electronics, 40(1), 23-36.

23. Wang, H., Li, S., Tian, Y. \& Aitouche, A. (2016). Intelligent Proportional Differential Neural Network Control for Unknown Nonlinear System, Studies in Informatics and Control, 25(4), 445-452. DOI: $10.24846 / \mathrm{v} 25 \mathrm{i} 4 \mathrm{y} 201605$ 
24. Wen, Y. K. (1976). Method for Random Vibration of Hysteretic Systems, Journal of the Engineering Mechanics Division, $102(2), 249-263$.

25. Xu, Y. L. (1996). Parametric study of active mass dampers for wind-excited tall buildings, Engineering Structures, 18(1), 64-76.

26. Yan, X.G., Spurgeon, S. K. \& Edwards, C. (2017). Variable Structure Control of Complex Systems Analysis and Design, Communications and Control Engineering. Springer International Publishing AG.
27. Young, K. D., Utkin, I. V. \& Özgüner, Ü. (1999). A Control Engineer's Guide to Sliding Mode Control, IEEE Transactions on Control Systems Technology, 7(3), 328-342.

28. Zizouni, K., Bousserhane, I. K., Hamouine, A. \& Fali, L. (2017). MR Damper-LQR control for earthquake vibration mitigation, International Journal of Civil Engineering and Technology, 8(11), 201-207.

29. Zizouni, K., Fali, L. Sadek, Y. \& Bousserhane, I. K. (2019). Neural network control for earthquake structural vibration reduction using MRD, Frontiers of Structural and Civil Engineering, 13(5), 1171-1182. 